\title{
Mitral valve replacement with the pulmonary autograft: Midterm results
}

\author{
Arkalgud Sampath Kumar, MCh, Sachin Talwar, MCh, and Anubhav Gupta, MCh
}

Objective: We performed mitral valve replacement with a pulmonary autograft using the technique described by us earlier and present the results.

\begin{abstract}
Methods: Between August 2000 and July 2007, 19 patients (16 male patients; age, 30-58 years) with isolated calcific mitral stenosis $(n=16)$ or mixed mitral stenosis and regurgitation $(n=3)$ underwent mitral valve replacement with a pulmonary autograft. Sixteen patients were in New York Heart Association class III and 3 were in New York Heart Association class IV preoperatively. Eight patients were in atrial fibrillation. The autograft implantation was achieved by using a scalloped stent of polytetrafluoroethylene felt for external support of the autograft. No anticoagulants were prescribed.

Results: There were 3 early deaths, one each caused by ventricular dysfunction, ventricular arrhythmias, and autograft dehiscence requiring early reoperation. Follow-up of survivors ranged from 34 to 99 months (mean, 71.9 \pm 18.2 months; median, 75 months). The mean valve area was $2.96 \pm 0.9 \mathrm{~cm}^{2}$ (range, $2.2-4.3 \mathrm{~cm}^{2}$ ). Fourteen survivors are in New York Heart Association class I, and 2 are in NYHA class II; 4 continue to be in atrial fibrillation. Follow-up echocardiograms $(\mathrm{n}=16)$, magnetic resonance imaging $(\mathrm{n}=6)$, and cardiac catheterization $(\mathrm{n}=4)$ have demonstrated no significant autograft and pulmonary homograft dysfunction. There were no late deaths or reoperations or thromboembolic complications.
\end{abstract}

Conclusions: Mitral valve replacement with a pulmonary autograft, a complex operation, can be performed in selected patients with acceptable results. The use of our technique of autograft implantation offers several advantages and avoids exposure of the scaffold to the bloodstream.

Mitral valve replacement with a pulmonary autograft (PAMVR) has been demonstrated to be a suitable option for patients requiring surgical intervention for mitral valve disease. The advantages of this procedure include durability, good hemodynamics, avoidance of anticoagulation, low incidence of thromboembolic complications, and suitability in the presence of infection. In a prior publication we presented our surgical technique and initial results with this procedure. ${ }^{1,2}$ Since then, our follow-up has increased, and we now present more detailed results with a longer follow-up in 19 consecutive patients over a 7-year period.

\section{MATERIALS AND METHODS}

Between August 2000 and July 2007, 19 patients (Table 1) underwent PA-MVR. All these patients had rheumatic mitral valve disease not amenable to mitral valve repair. Preoperative transthoracic echocardiographic

\footnotetext{
From the Cardiothoracic Centre, All India Institute of Medical Sciences, New Delhi, India.

Received for publication July 12, 2008; revisions received Sept 21, 2008; accepted for publication Nov 25, 2008; available ahead of print March 27, 2009.

Address for reprints: Arkalgud Sampath Kumar, MCh, Department of Cardiothoracic and Vascular Surgery, Cardiothoracic Centre, All India Institute of Medical Sciences, Ansari Nagar, New Delhi 110 029, India (E-mail: asampath_kumar@ hotmail.com).

J Thorac Cardiovasc Surg 2009;138:359-64

$0022-5223 / \$ 36.00$

Copyright (C) 2009 by The American Association for Thoracic Surgery

doi:10.1016/j.jtcvs.2008.11.063
}

analysis was performed in all patients and revealed severe rheumatic mitral stenosis with a mitral valve area of less than $1.0 \mathrm{~cm}^{2}$ in 15 patients; 1 patient had a mitral valve area of $1.2 \mathrm{~cm}^{2}$. Mitral valve calcification was seen on fluoroscopic analysis in 16 patients. Combined mitral stenosis and mitral regurgitation was present in 3 patients. Three patients had evidence of a thrombus in the left atrium and were receiving oral anticoagulants. Insignificant aortic regurgitation was present in 2 patients. Three patients had moderate tricuspid regurgitation caused by pulmonary arterial hypertension. Mean left atrial (LA) size was $51.4 \pm 9.9 \mathrm{~mm}$ (range, 39-84 mm; median, 48 $\mathrm{mm}$ ). Four patients had LA sizes of between 39 and $45 \mathrm{~mm}, 6$ patients had LA sizes of between 46 and $50 \mathrm{~mm}, 7$ patients had LA sizes of between 51 and $60 \mathrm{~mm}$, and 2 patients had LA sizes of greater than $60 \mathrm{~mm}$. The mean left ventricular end-systolic dimension was $21.1 \pm 4.4 \mathrm{~mm}$ (range, 25-40 $\mathrm{mm}$; median $28 \mathrm{~mm}$ ), and the mean left ventricular end-diastolic dimension was $46.5 \pm 9.3 \mathrm{~mm}$ (range, $34-80 \mathrm{~mm}$; median, $45 \mathrm{~mm}$ ). The mean left ventricular ejection fraction was $58.4 \% \pm 3.9 \%$ (range, $55 \%-70 \%$; median, $60 \%$ ). Cardiac catheterization and cineangiography were performed if there was suspicion of associated aortic valve or coronary artery disease. All these patients had evidence of severe pulmonary hypertension (mean pulmonary artery pressure, $67 \mathrm{~mm} \mathrm{Hg}$ ) and severe pulmonary venous hypertension (mean pulmonary capillary wedge pressure, $36 \mathrm{~mm} \mathrm{Hg}$ ).

\section{Patient Selection}

Informed consent was obtained from all patients. We offered this procedure only to rheumatic subjects more than 30 years of age because of concerns of involvement of the pulmonary valve with the rheumatic disease process, which we observed in our prior experience with aortic valve replacement with a pulmonary autograft. ${ }^{3}$ The procedure was not considered in patients with a bicuspid pulmonary valve or pulmonary regurgitation. Other exclusion criteria included (1) previous reoperation because the harvesting of the autograft might be difficult as a result of adhesions, (2) associated aortic valve disease requiring intervention, (3) associated coronary 


$$
\begin{aligned}
& \text { Abbreviations and Acronyms } \\
& \begin{aligned}
\text { AF } & =\text { atrial fibrillation } \\
\text { LA } & =\text { left atrial } \\
\text { MRI } & =\text { magnetic resonance imaging } \\
\text { MVR } & =\text { mitral valve replacement } \\
\text { PA-MVR } & =\text { mitral valve replacement with a } \\
& \text { pulmonary autograft }
\end{aligned}
\end{aligned}
$$

artery disease, (4) significant left ventricular dysfunction, (5) requirement of an emergency operation, (6) requirement of reoperation for prosthetic valve endocarditis, (7) presence of native valve endocarditis with significant left ventricular dysfunction, and (8) age greater than 60 years (bioprostheses were preferred in these patients). Preoperative atrial fibrillation (AF) was not a contraindication. A small left atrium was not a contraindication, and 10 of the 19 patients had LA sizes of less than $50 \mathrm{~mm}$. This might, however, be an important consideration in the pediatric age group when this operation is offered to children with congenital mitral stenosis.

Intraoperative transesophageal echocardiographic analysis was performed with a Hewlett-Packard Sonos 1500, 2500, or 5500 ultrasound system (Hewlett-Packard Co, Andover, Mass). The echocardiographic assessment included a systematic study of the annulus, leaflet thickness and mobility, commissural and chordal fusion, presence of calcification, regurgitant jet, thickness of the chordae tendinae, and presence of clots in the left atrium or the LA appendage. Other valves were also assessed in a systematic fashion. Special attention was directed to the pulmonary valve because a bicuspid pulmonary valve or pulmonary regurgitation was a contraindication.

\section{Surgical Technique}

For more information on surgical technique, see Figures 1 and 2. The surgical approach was through a median sternotomy and vertical pericardiotomy in all patients. The pulmonary artery was dissected and looped. Moderately hypothermic $\left(28^{\circ} \mathrm{C}\right)$ cardiopulmonary bypass was established, and cold antegrade cardioplegia and topical cooling were used for myocardial preservation. After a left atriotomy, the LA thrombus, if present, was removed. The mitral valve was inspected, and if repair was not feasible, it was excised with preservation of both the anterior and posterior chordae and subvalvular apparatus in all patients by using the technique of Miki and colleagues. ${ }^{4}$ The pulmonary autograft was then harvested in a standard fashion and sized with a homograft sizer. The technical details of PA-MVR were described by us in detail earlier ${ }^{1}$; however, the salient features are summarized.

We did not place the autograft in a prosthetic tube, as advocated by others. ${ }^{5,6}$ Instead, an appropriately sized stent was prepared with thick, nonporous Teflon felt (CR Bard, Inc, Delran, NJ), the circumference of which was measured with an appropriate sizer. Its height was measured to adjust to the height of the pulmonary valve commissures. When the stent ends were closed, this formed a ring support for the autograft. Three interrupted sutures were passed through the mitral annulus at equidistant points and then into the top of the autograft commissures. After this, the autograft was inverted into the left ventricle and sutured to the mitral annulus with a continuous suture. Sutures were then passed from the autograft commissures $2 \mathrm{~mm}$ below the pillars and into the Teflon stent and through the LA wall, which was gathered $2 \mathrm{~cm}$ upstream of the mitral annulus. After running the sutures in a continuous fashion and tying them, the ring stent was incorporated between the autograft and the LA wall without being exposed to the bloodstream. The newly created mitral valve was now tested for competence by injecting cold saline into the left ventricular cavity with a bulb syringe with the aortic root vent open, and coaptation of leaflets was observed. The left atrium
TABLE 1. Profile of patients undergoing mitral valve replacement with the pulmonary autograft

\begin{tabular}{lc}
\hline Male/female sex & $14 / 5$ \\
Age $(y)$ & $30-58$ (mean, $42.8 \pm 7.8 ;$ median, 40$)$ \\
Symptoms & \\
$\quad$ Dyspnea & $19(100 \%)$ \\
Palpitations & $16(84.2 \%)$ \\
CHF & $12(63.2 \%)$ \\
NYHA class & \\
III & $16(84.2 \%)$ \\
IV & $3(15.8 \%)$ \\
Clinical diagnosis & \\
Calcific mitral stenosis & $16(84.2 \%)$ \\
Mitral stenosis + regurgitation & $3(15.8 \%)$ \\
Moderate TR & $3(15.8 \%)$ \\
Atrial fibrillation & $8(42 \%)$ \\
\hline
\end{tabular}

$\overline{C H F}$, Congestive heart failure; NYHA, New York Heart Association; TR, tricuspid regurgitation.

was closed, and the right ventricular outflow tract was reconstructed with an appropriately sized cryopreserved pulmonary homograft from our own valve bank (Table 2). Immediate postoperative transesophageal echocardiographic analysis was performed in all the patients to confirm that the autograft and homograft were functioning satisfactorily. The mean aortic crossclamp and cardiopulmonary bypass times were 118.6 \pm 17.2 minutes (range, 63-140 minutes) and 145.2 \pm 13 minutes (range, 119-174 minutes), respectively.

No surgical procedure was performed for AF. However, internal cardioversion was attempted in all patients with $\mathrm{AF}$ on the operating table by using direct internal defibrillator paddles connected to an external DC defibrillator.

\section{Follow-up}

Before discharge from the hospital, transthoracic echocardiographic analysis was performed in all patients, and this procedure was repeated at 6-month intervals. Mitral regurgitation was graded as none, mild, moderate, or severe according to published criteria. ${ }^{7}$ Autograft degeneration was considered as valve area less than $1.5 \mathrm{~cm}^{2}$ or more than mild regurgitation through the autograft. The pulmonary homograft was also assessed, and peak gradients of less than $20 \mathrm{~mm} \mathrm{Hg}$ across the pulmonary valve were considered mild pulmonary stenosis. A peak transvalvular gradient of 50 $\mathrm{mm} \mathrm{Hg}$ or greater across the pulmonary valve was considered significant pulmonary stenosis.

No anticoagulants or antiplatelet drugs were prescribed. All patients less than 45 years of age with rheumatic heart disease received long-acting benzathine penicillin until 45 years of age. All patients received itraconazole for 6 weeks after surgical intervention as prophylaxis against fungal endocarditis.

\section{Statistical Analysis}

Statistical analysis was performed with the SPSS for windows 11.5 software package (SPSS, Inc, Chicago, Ill). Descriptive statistics (ie, mean and standard deviation) have been calculated for the continuous variables. Freedom from valve-related events and actuarial estimates have been calculated by using the Kaplan-Meier analysis. A valve-related event was defined as any episode of thromboembolism, hemorrhage, congestive heart failure, infective endocarditis, structural deterioration, or significant gradients, as per published criteria. ${ }^{8}$ The period between July 2007 and June 2008 was the closing interval for the study, and the follow-up status of the patients during this period was used for statistical analysis. 


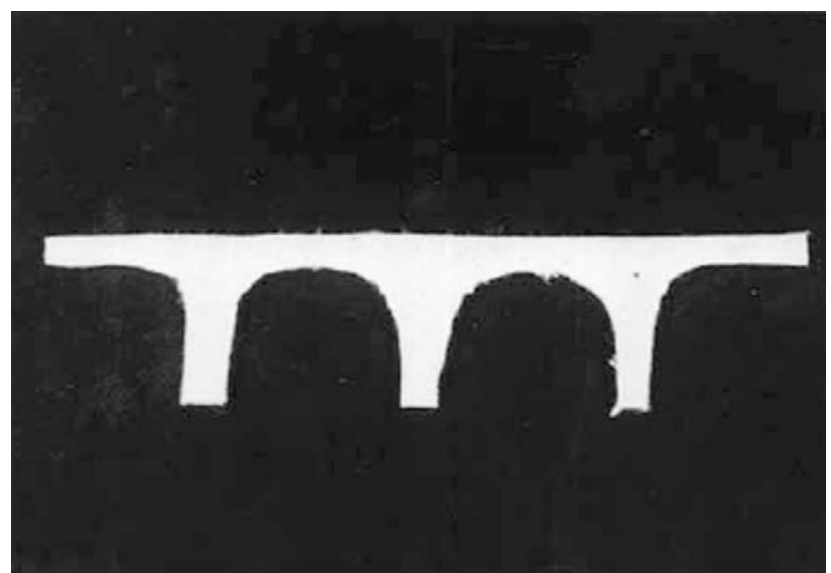

FIGURE 1. The stent designed from thick, nonporous Teflon felt. Reprinted from J Thorac Cardiovasc Surg. 2001;122:378-9. Copyright 2001 with permission from the American Association for Thoracic Surgery.

\section{RESULTS}

\section{Hospital Mortality}

All patients could be uneventfully weaned off cardiopulmonary bypass with satisfactory autograft function on transesophageal echocardiographic analysis. However, there were 3 early deaths. The first death occurred in a 34-yearold patient who had acute pulmonary edema caused by severe mitral regurgitation on the third postoperative day. At the time of reoperation, dehiscence of the proximal suture line was observed and successfully repaired. However, the patient experienced irreversible myocardial failure and died. The second death occurred in a 50-year-old patient who had an uneventful postoperative course and experienced sudden intractable ventricular tachyarrhythmia on the 10th postoperative day and died. The third death occurred in a 38-year-old patient who died on the fourth postoperative day as a result of severe biventricular dysfunction. In all 3 patients, permission for autopsy was denied by the family.

\section{Early Reoperation}

As detailed above, 1 patient required reoperation for autograft dehiscence. Two patients required reoperations for excessive mediastinal bleeding. In one of these patients, the bleeding source was the raw surface of the posterior wall of the right ventricular outflow tract, and in another patient it was from the edges of the pleura.

\section{Hospital Course}

Apart from the above, the other patients had an uneventful postoperative course. Of the 8 patients with preoperative $\mathrm{AF}$, sinus rhythm was restored in 4 , and the rest continued to be in AF. Minor sternal wound infection was encountered in 1 patient. The mean intensive care unit stay was $2.8 \pm 1.7$ days

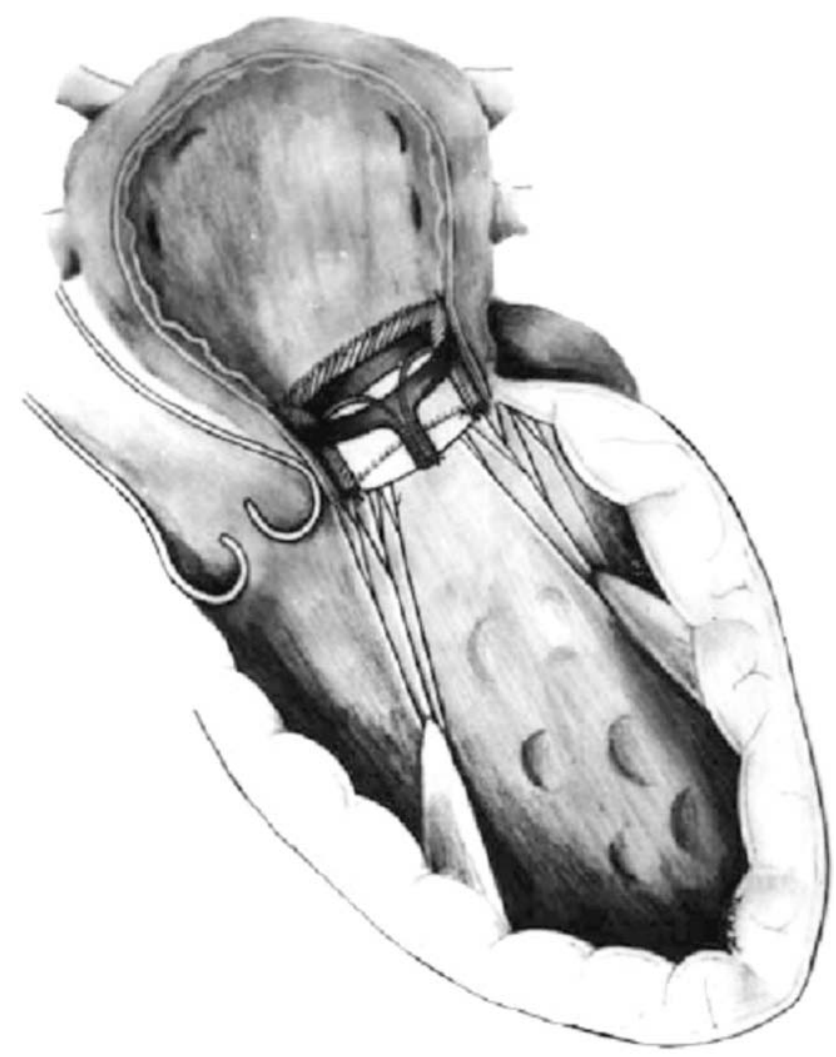

FIGURE 2. Diagram of the completed autograft implantation. Reprinted from J Thorac Cardiovasc Surg. 2001;122:378-9. Copyright 2001 with permission from the American Association for Thoracic Surgery.

(range, 2-6 days; median, 2 days), and the mean hospital stay was $7.9 \pm 2.8$ days (range, 5-15 days; median, 7 days).

\section{Follow-up}

All patients were seen in the outpatient clinic at 6-month intervals and underwent clinical examination and echocardiographic analysis. Between December 2007 and June 2008 , the records of all the patients were obtained, and their most recent status during this period was analyzed for reporting the results. The follow-up data ( $100 \%$ complete) ranged from 34 to 99 months (mean, $71.9 \pm 18.2$ months; median, 75 months) and totaled 95.9 patient-years. Among survivors, $9(56.3 \%)$ were followed up for 6 or more years, $3(18.7 \%)$ were followed for 5 or more years, and $4(25 \%)$ were followed up for more than 2 years.

TABLE 2. Intraoperatively measured size of the pulmonary autografts and pulmonary homografts

\begin{tabular}{lcc}
\hline Size (mm) & Pulmonary autograft (n) & Pulmonary homograft size (n) \\
\hline 24 & 3 & 5 \\
26 & 5 & 9 \\
28 & 6 & 4 \\
29 & 1 & - \\
30 & 4 & 1 \\
\hline
\end{tabular}


TABLE 3. Postoperative echocardiographic findings in $\mathbf{1 6}$ survivors undergoing mitral valve replacement with the pulmonary autograft

\begin{tabular}{lcc}
\hline \multicolumn{1}{c}{ Parameter } & Before discharge & At last follow-up \\
\hline Mitral valve area $\left(\mathrm{cm}^{2}\right)$ & $3.15 \pm 0.8(2.2-4.8)$ & $2.96 \pm 0.9(2.2-4.3)$ \\
Mitral stenosis & None & None \\
Mean mitral gradient $(\mathrm{mm} \mathrm{Hg})$ & $4 \pm 0.2(1-4)$ & $3.4 \pm 1.5(2-5)$ \\
Mitral regurgitation & & \\
$\quad$ None & 15 & 12 \\
Mild & 1 & 3 \\
$\quad$ Moderate & 0 & 1 \\
PA peak gradient $(\mathrm{mm} \mathrm{Hg})$ & $10 \pm 7.9(0-20)$ & $15 \pm 8.5(10-20)$ \\
Pulmonary regurgitation & None & None \\
\hline
\end{tabular}

$P A$, Pulmonary artery.

\section{Autograft Function and Fate of the Right Ventricular Outflow Tract}

Echocardiographic data at the time of discharge from the hospital and at follow-up in the closing interval are presented in Table 3. It is apparent that the autograft performed well, with no evidence of degeneration. Similarly, there was no pulmonary stenosis or regurgitation.

Six patients consented to magnetic resonance imaging (MRI) and 4 to cardiac catheterization and cineangiography. MRI findings in these patients are particularly interesting. As described by us earlier, ${ }^{9}$ it clearly shows the autograft wholly in the left atrium, which extends at least $2 \mathrm{~cm}$ upstream of the mitral annulus. Therefore the valve cusps of the autograft are at a higher level compared with the tricuspid valve, as seen in these images (Figure 3). Echocardiography, MRI, and cineangiography have clearly demonstrated no significant autograft and pulmonary homograft dysfunction.

\section{Survival and Functional Status}

There were no late deaths. Fourteen survivors are in New York Heart Association class I, and 2 are in NYHA class II; 4 continue to be in AF. There were no thromboembolic complications, hemolysis, or infective endocarditis in the survivors, and no reoperations were required in the follow-up period.

The actuarial and event-free survival (Figure 4) at a median follow-up of 75 months was $89.47 \% \pm 7 \%$ (95\% confidence interval, $75 \%-98 \%$ ).

\section{DISCUSSION}

An ideal substitute for the irreparable mitral valve has not yet been found. As for a valve substitute in any position, such a substitute should be easily available, be inexpensive, provide hemodynamics comparable with those of the natural human mitral valve, have the ability to remodel, and be resistant to infection and must not propagate thromboemboli and be free from the hazards of anticoagulation. In growing children it should grow with the patient. In pursuit of this goal, Ross first described the PA-MVR (Ross II procedure)

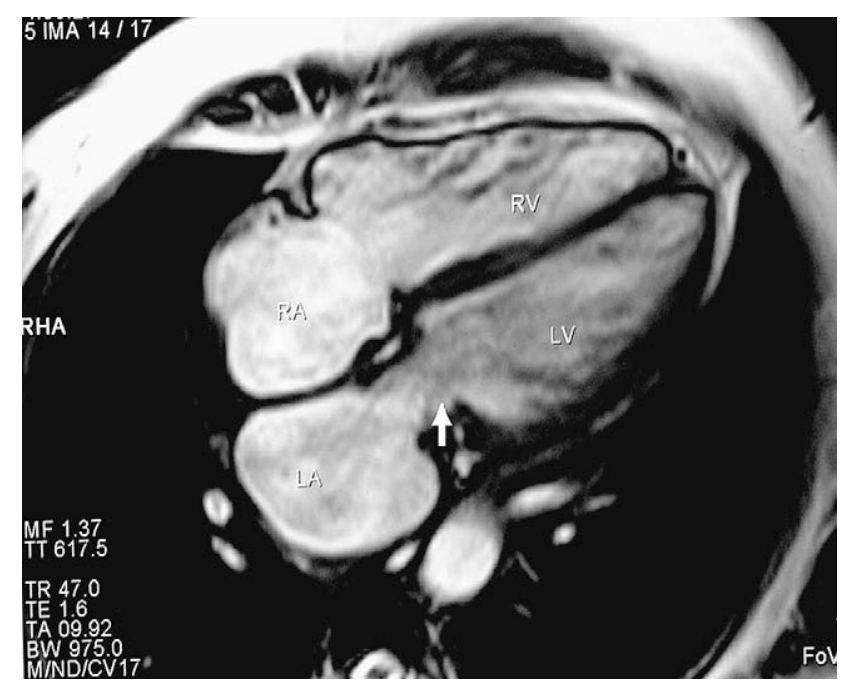

FIGURE 3. Gradient echocardiographic pulse sequence (true-FISP) cine magnetic resonance image in the 4-chamber view (diastolic frame): the pulmonary autograft is shown in the mitral position (arrow). Note the level of the new "mitral valve," which is higher than that of the tricuspid valve. $R V$, Right ventricle; $R A$, right atrium; $L V$, left ventricle; $L A$, left atrium. Reprinted from Tex Heart Inst J. 2004;31:326-7. Copyright 2004 with permission from the Texas Heart Institute Journal.

in $1967 .{ }^{10}$ He subsequently performed 8 such procedures between 1967 and 1971, and in 1997, 4 of the 7 patients were asymptomatic and reoperation free for more than 10 years. ${ }^{11}$ Yacoub and Kittle ${ }^{12}$ used an aortic homograft placed inside a Dacron tube for mitral valve replacement (MVR), and Elkins $^{13}$ used a pulmonary homograft for this purpose. However, the techniques of PA-MVR were popularized by Kabbani and coworkers, ${ }^{5,11,14}$ who have aggressively pursued this operation and have described its technical aspects in great detail. This operation has since been adopted by many groups, and experience with these patients

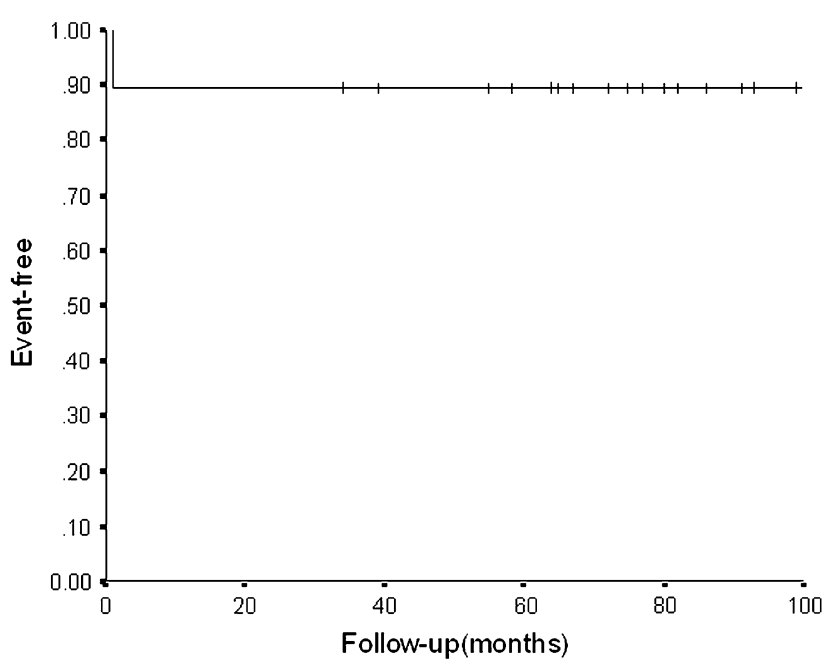

FIGURE 4. Event-free survival in patients undergoing the Ross II procedure. 
continues to evolve. ${ }^{6,15,16}$ Because the procedure is technically demanding, failures have occurred and have been dealt with by instituting a number of technical modifications. The initial procedures were performed by using the "top-hat technique," 12 with the autograft being completely placed in the left atrium rather than the left ventricle to facilitate easier suturing and to prevent left ventricular outflow tract obstruction. As pointed out by Kabbani and colleagues, ${ }^{14}$ the Achilles heel of this operation is conduit obstruction caused by angulation of the soft Dacron tubing material inside which the autograft is placed. The "miniskirt" technique was proposed in which the pericardium is placed over the woven Dacron graft to minimize this. ${ }^{17}$ This saved operative time and was considered low risk. Current modifications include the use of surgical glue in this miniskirt pericardial configuration in between the Dacron and the pericardial tissue to achieve firmness. ${ }^{14}$

We have not used this technique and have developed our own technique in which a stent fashioned out of Teflon felt is used to support the autograft. There are a number of advantages of this technique. There is no risk of kinking of the Dacron tube, which can produce immediate autograft failure. The stent is completely buried and does not come into contact with the bloodstream, thus minimizing the risk of thromboembolic complications. Prophylactic anticoagulants are therefore not required, which is a major advantage. Although we have not performed this procedure in children, the advantage of avoiding anticoagulants, even in the short term, in children is important. We have also observed the autograft sinuses to billow during valve closure in the ventricular systole on echocardiographic analysis, which might indicate that this technique might help in the growth potential of the autograft, an advantage that might not be obtained when the autograft is encased in a tube. Making slits in the side of the tubing has been reported to preserve the growth potential, particularly in children; however, long-term follow-up data are not available to demonstrate this advantage.

Concerns have been voiced on the growing popularity of PA-MVR. ${ }^{18}$ Long-term follow-up data are not available, although Kabbani and colleagues ${ }^{14}$ have recently reported a freedom from autograft degeneration of $93.4 \%$ at 5 years' follow-up. Others have also reported encouraging results. ${ }^{6,15,16}$ In the older age group bioprostheses are still the substitutes of choice because they are technically easier to implant, with a lower operative risk and proved long-term results. ${ }^{19}$ Although Kabbani and colleagues ${ }^{14}$ project similar durability when compared with bioprostheses, there is no firm clinical evidence to this effect. The issue of long-term durability compared with that of a bioprosthesis will only become clear with longer follow-up. Also, there is no evidence presently that the autograft is resistant to infective endocarditis because deaths have been reported as a result of this complication. However, PA-MVR is free from some of the disadvantages of the bioprosthesis, namely rapid de- generation in younger patients, the presence of a high-profile stent, less effective orifice area in small sizes, and the possibility of left ventricular outflow tract obstruction and rhythm disturbances in patients with smaller hearts. ${ }^{6}$

This procedure might be suitable for children in whom other valve substitutes are not the preferred option, although its growth in children has not been studied. We are in agreement with the experience of others that PA-MVR is a suitable option for a select group of patients with rheumatic mitral valve disease, particularly in developing countries. The operation can be accomplished at a much reduced cost compared with the use of prosthetic valves and avoids the costs and hazards of anticoagulation. In many developing countries the majority of the patients live in rural areas and have limited or no access to centers in which anticoagulation can be reliably monitored. Freedom from anticoagulation eliminates the risk of anticoagulant-related hemorrhage and also prosthetic valve dysfunction and sudden death caused by inadequate anticoagulation, as seen with mechanical prostheses. The procedure does take much longer to perform than MVR with a mechanical prosthesis or a bioprosthesis, but the costs in the longer term are much less because of avoidance of anticoagulation, need to travel to distant hospitals for conducting tests to monitor anticoagulation, and elimination of the risks of anticoagulant-related hemorrhage, which might impose significant morbidity and keep patients away from work. We do not regard preoperative $\mathrm{AF}$ as a contraindication to this operation, and we do not prescribe oral anticoagulants, even to those patients who continue to remain in AF. We have followed this policy successfully over the last decade in patients undergoing mitral valve repair and MVR with bioprostheses and have not observed any deleterious effects. ${ }^{20,21}$

The final concern is that of converting a single-valve operation into a 2-valve procedure because of the placement of a pulmonary homograft. However, our midterm to long-term results of the Ross operation for aortic valve disease ${ }^{22}$ have not demonstrated any significant degeneration of the conduits in the pulmonary position, and this has encouraged us to offer this procedure to rheumatic patients with mitral valve disease not amenable to repair. We have, however, not used this operation in patients younger than 30 years because of concerns about the involvement of the pulmonary valve by the rheumatic process.

\section{Limitations}

An important limitation of our study is that the patient population is highly selected, and the number of patients is small. Availability of homografts is the limiting factor in our present practice, and we might be able to increase the number of these procedures once a regular supply of homografts is assured. When homografts are procured and preserved locally by developing valve banks, further reduction can be made in the cost of this procedure by 
avoiding the costs of a prosthetic valve. Also, we have no experience with this operation in the pediatric age group. The operation is technically complex and is associated with a learning curve. Once these limitations are overcome, the procedure is very cost-effective. We had 3 deaths in 19 patients, and in one of these 3 , death was due to autograft dehiscence in the early part of our experience. The other 2 deaths were due to ventricular arrhythmia and severe biventricular dysfunction and were probably not related to the choice of the substitute because both these patients had severe pulmonary hypertension. The mortality also appears to be disproportionately high because of the small number of patients. However, we do believe that with increasing experience, mortality can be brought down, as indicated by Kabbani and colleagues, ${ }^{14}$ who report a mortality of only $4.5 \%$ in their large experience.

\section{CONCLUSION}

PA-MVR, a complex operation, can be performed in selected patients with acceptable results. The use of our technique of autograft implantation offers several advantages.

We thank our colleagues from the Department of Cardiology for the meticulous follow-up echocardiographic evaluation of these patients.

\section{References}

1. Kumar AS, Aggarwal S, Choudhary SK. Mitral valve replacement with the pulmonary autograft: the Ross II procedure. J Thorac Cardiovasc Surg. 2001;122: 378-9.

2. Roy S, Mohanty A, Kumar AS. Pulmonary autograft mitral valve replacement: initial experience with the Ross II procedure. Indian Heart J. 2002;54:276-8.

3. Choudhary SK, Mathur A, Sharma R, Saxena A, Chopra P, Roy R, et al. Pulmonary autograft: should it be used in young patients with rheumatic disease? J Thorac Cardiovasc Surg. 1999;118:483-90.

4. Miki S, Ueda Y, Tahata T, Okita Y. Mitral valve replacement with preservation of chordae tendineae and papillary muscles. Ann Thorac Surg. 1995;60:225-6.
5. Kabbani SS, Jamil H, Hammoud A, Hatab JA, Nabhani F, Hariri R, et al. The mitral pulmonary autograft: assessment at midterm. Ann Thorac Surg. 2004;78:60-5.

6. Brown JW, Ruzmetov M, Rodefeld MD, Turrentine MW. Mitral valve replacement with Ross II technique: initial experience. Ann Thorac Surg. 2006;81:502-7.

7. Helmcke F, Nanda NC, Hsiung MC, Soto B, Adey CK, Goyal RG, et al. Color Doppler assessment of mitral regurgitation with orthogonal planes. Circulation. 1987;75:175-83.

8. Edmunds LH, Clark Re, Cohn LH, Grunkemeier GL, Miller DC, Weisel RD. Guidelines for reporting morbidity and mortality after cardiac valvular operations. J Thorac Cardiovasc Surg. 1996;112:708-11.

9. Gulati GS, Sharma S, Jagia P, Talwar S, Kumar AS. Magnetic resonance imaging of a pulmonary autograft in the mitral position. Tex Heart Inst J. 2004;31:326-7.

10. Ross DN. Replacement of aortic and mitral valves with a pulmonary autograft. Lancet. 1967;2:956-8.

11. Kabbani SS, Jamil H, Hammoud A, Nabhani F, Hariri R, Sabbagh N, et al. Use of the pulmonary autograft for mitral replacement: short- and medium-term experience. Eur J Cardiothorac Surg. 2001;20:257-61.

12. Yacoub MH, Kittle CF. A new technique for replacement of the mitral valve by a semilur valve homograft. J Thorac Cardiovasc Surg. 1969;58:859-69.

13. Elkins RC. Ross operation-history, indications, results, concerns. Contemp Surg. 1999;54:306-18.

14. Kabbani S, Jamil H, Nabhani F, Hamoud A, Katan K, Sabbagh N, et al. Analysis of 92 mitral pulmonary autograft replacement (Ross II) operations. J Thorac Cardiovasc Surg. 2007;134:902-8.

15. Athanasiou T, Cherian A, Ross D. The Ross II procedure: pulmonary autograft in the mitral position. Ann Thorac Surg. 2004;78:1489-95.

16. Al Halees Z, Awad MM, Pieters F, Shahid MS, Al Amri MA. Six-year follow-up of a pulmonary autograft in the mitral position: the Ross II procedure. J Thorac Cardiovasc Surg. 1999;117:614-6.

17. Kabbani SS, Jamil H, Hammoud A. Technique for replacing the mitral valve with a pulmonary autograft: the Ross-Kabbani operation. Ann Thorac Surg. 2001;72: 947-50.

18. Filsoufi F, Adams DH. Invited commentary. Ann Thorac Surg. 2004;78:65-6

19. Marchand MA, Aupart MR, Norton R, Goldsmith IR, Pelletier LC, Pellerin M, et al. Fifteen-year experience with the mitral Carpentier-Edwards PERIMOUNT pericardial bioprosthesis. Ann Thorac Surg. 2001;71(suppl):S236-9.

20. Kumar AS, Talwar S, Saxena A, Singh R, Velayoudam D. Results of mitral valve repair in rheumatic mitral regurgitation. Interact Cardiovasc Thorac Surg. 2006; 5:356-61.

21. Talwar S, Sharma A, Kumar AS. Tissue heart valve implantation in India; indications, results and impact on quality of life. Ind J Thorac Cardiovasc Surg. 2008; 24:10-4.

22. Kumar AS, Talwar S, Mohapatra R, Saxena A, Singh R. Aortic valve replacement with the pulmonary autograft: mid-term results. Ann Thorac Surg. 2005;80: 488-94. 